\title{
News
}

\section{Newspaper investigation highlights bioterror fears}

UK firm unknowingly synthesizes smallpox fragment.

Oliver Morton

A recent investigation in a UK newspaper has highlighted the gulf between what is utterly routine within the research and biotech communities and what can shock the outside world, including legislators.

In a front-page article in The Guardian on 14 June, the newspaper's science correspondent describes how he arranged for a tiny fragment of the smallpox genome to be synthesized by a mail-order biological-supplies company and delivered to his home address. The company involved, VH Bio, based in Gateshead, UK, did not screen the sequence using software that checks orders against the genomes of dangerous microorganisms.

The ordering of short pieces of DNA from companies is an everyday occurrence in labs around the world; VH Bio says that it deals with hundreds of such orders a day, and it is far from the largest player in the market.

The 78-base-pair smallpox fragment (an oligonucleotide, or oligo in the trade) was not, in itself, dangerous. Its sequence described a small part of the virus's coat protein, rather than anything specifically disease-related, and had been edited in such a way as to make it impossible for the protein-making machinery in cells to read it.

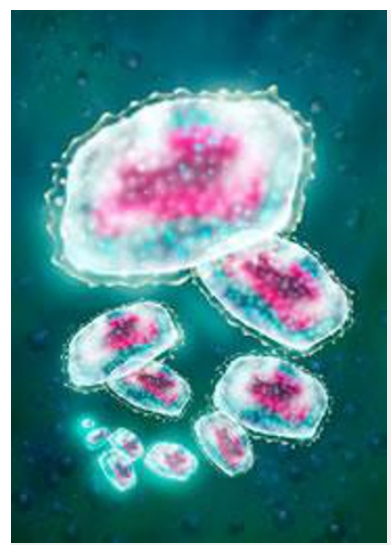

Smallpox viruses are large and complex, but might still be synthesised from scratch in a determined lab.

C $S P L$

VH Bio says that it checks the backgrounds of people and companies making large orders, but doesn't use its most stringent checks for small orders like The Guardian 's. When the company ran screening tests on the sequence retrospectively, comparing it to databases containing known pathogens, it says that the alarm bells still stayed silent. This came as a surprise to Robert Jones, a security specialist based in Seattle whose company has designed software that a number of 'synthetic biology' companies use to screen sequences. Jones helped The Guardian make sure the sequence was safe, and also designed it in such a way that it should have been picked up as smallpox-related by straightforward database comparisons, as well as by his more specialised software.

\section{Inside track}

The smallpox virus was eradicated from the wild in the 1970s, although some samples remain in labs. The virus's genome is much larger than that of the poliovirus, which was recreated in 2002 using similarly sized mail-order oligos by Eckard Wimmer at the State University of New York, Stony Brook 1 . To recreate smallpox from oligos of the size bought by The Guardian would require about 3,500 separate orders and the skills typically found in a university biology lab. It would be a large and costly operation, according to Wimmer, but not impossible.

Indeed, whole viruses have already been synthesized: notably by Wimmer, by Craig Venter 2 , and by the group that recreated the 1918 flu virus $\underline{3}$. When Wimmer published his work four years ago, he argued that checking oligo sequences against known pathogens would be a good idea. Drew Endy, a synthetic biologist at the Massachusetts Institute of Technology in Cambridge, points out that those earlier achievements had already highlighted the possibilities reported by The Guardian. However, they had not demonstrated so clearly to the world outside the laboratory how easy it is to get any DNA sequence you might want manufactured.

Given that the issues have already been widely discussed, and that the synthetic biology community is attempting to address them itself(see Synthetic biologists try to calm fears ), Endy is unimpressed by The Guardian article. "It slightly increases the risk of another stunt, and as such is irresponsible," he says. Bradley Smith, of the University of Pittsburgh's Center for Biosecurity in Baltimore, Maryland, is more sanguine. "It's not necessarily inappropriate to try to stimulate the debate — it was intended to grab attention and we'll see how that plays out." Endy notes, however, that "the debate is, unfortunately, extremely dramatic already".

Endy is particularly concerned that ill thought-through regulation might make the situation worse, not just in terms of hampering researchers, but also by driving the technology underground into grey or black markets. It is quite possible to buy or to build a DNA synthesizer if need be, and if commercial oligos get harder to buy, more people may do so. "It's not a straightforward lock-things-down situation," he says, "you could make things significantly worse that way." On the morning that The Guardian reported having bought its oligo for US\$61.11, there were oligo-synthesizing machines available on web auction sites for less than $\$ 1,000$ that could make any number of the things.

\section{Visit our investigationhighli.html">newsblog to read and post comments about this story.}

\section{References}

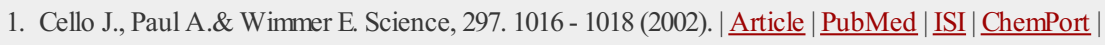


2. Smith H., Hutchison C., Pfannkoch C.\& Venter J.et al. Proc. Natl Acad. Sci. USA, 100. 15440 - 15445 (2003). $|\underline{\text { Article }}| \underline{\text { PubMed }}|\underline{\text { ChemPort }}|$

3. Tumpey T. M., et al. Science, 310.77 - 80 (2005). $\mid$ Article $|\underline{\text { PubMed }}| \underline{\text { ISI } \mid \text { ChemPort } \mid}$ 